Review

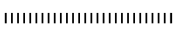

\title{
Contemporary Issues on Pesticide Safety
}

\author{
Fumio MatsumurA* \\ Department of Environmental Toxicology, University of California Davis, \\ One Shields Avenue, Davis, California 95616, USA
}

(Received June 15, 2004)

\begin{abstract}
At any given moment there are always new issues on pesticide safety. Some of those issues are forced by the society based on the emergence of new threats, the changing attitude of the general public or complaints by action groups representing special interests of certain sub-populations. Others are the results of new scientific discoveries, technological development and/or introduction of new compounds. In this paper an effort has been made to analyze some of the recent issues from the viewpoint of categorizing them into several major types of safety issues in order to clarify the reason behind those issues, and thereby to assist the process of achieving the balance of effective use of pesticides and their safety. C Pesticide Science Society of Japan
\end{abstract}

Keywords: pesticide safety, risk assessment, social attitude, gnenetically modified crops, scientific discoveries.

\section{INTRODUCTION}

Pesticides are one of the most strictly regulated classes of chemicals in most societies, and therefore the fact that new issues on their safety are continuously raised troubles some pesticide scientists. Many of those questioned pesticides have been used for long time periods with good safety records, and yet still new issues on their safety could be raised at any time. To be sure some of those issues are raised by the uninformed public or are old questions already solved before, needing only the continued efforts to educate the public. Yet, many of the issues raised in recent years on existing pesticides are genuinely new. For example, the issue of endocrine disruptors in the environment applied to many existing pesticides. The key question one must raise is why we have not raised those questions before or how many more questions could be cropping up in the near future?

The main objective of this paper is to analyze the pattern of new issues being generated, identify the reasons behind those, and thereby to provide the means to anticipate and deal with those new issues.

\section{INTRODUCTION OF BRAND NEW TECHNOLO- GIES OR PESTICIDES}

Of all the new issues probably this is the type which is most easily understood why new questions are raised by the public

\footnotetext{
* To whom correspondence should be addressed.

E-mail: fmatsumura@ucdavis.edu

CPesticide Science Society of Japan
}

and the governments, because they are naturally nervous about unknowns. Perhaps the best example would be the introduction of genetically modified (GM) crops for the first time to a society. Indeed, not so surprisingly, there have been many heated discussions, new demands for additional experiments to address key issues, and hence development of new sets of guidelines. ${ }^{1)}$

The most pertinent observation has been that there are sharp differences in the attitude of people among different societies towards this issue of introduction of GM crops into their environment. It is generally considered that the American public in general is willing to accept the risks associated with introduction of new GM crops as compared to the European counterpart. For instance, in the case of the American scientists (e.g. those involved in the EPA Scientific Advisory Panel meetings); the major issue raised against corn genetically modified to express the Bacillus thuringiensis toxin (Bt toxin) has been the possibility of allergic reactions induced in people consuming the toxin. ${ }^{2}$ The past safety records of the use of Bacillus thuringiensis spores themselves have been considered to offer enough evidence to judge the safety of the toxins in the GM corn varieties, including the newly approved $\mathrm{Bt}$ toxin in the YieldGuard corn variety aimed at control of corn rootworms. In this case of newly approved use of genetically modified corn for rootworm control, the only condition being demanded is the planting of $20 \%$ or more of normal corn to provide insect refugia for prevention of resistance development and the initial use period for 3 years.

In contrast, the process of adopting GM plants in Europe has been extremely tedious. Certainly, the most likely reason 
for such differential responses is the basic difference in the social attitude toward genetically modified organisms between these two societies. The initial main concern in Europe appeared to be the safety of the GM crop to the health of human consuming. Even when such a fear has been reasonably discounted by scientists as in the case of the United Kingdom, ${ }^{3)}$ a new suspicion on the ecological effects of GM crops has emerged... For instance, in the recently completed field trials on 3 GM crops (corn, oilseed rape and sugar beets), the main question asked in the UK now is the maintenance of ecological diversity in the farm scaled experimental plots as compared to normal crops planted side by side. ${ }^{4)}$ The results showed that only in GM corn fields more diverse weed populations ( $82 \%$ more) were observed than those found in regular corn fields. In contrast GM beet and oilseed rape fields showed 60 and $80 \%$ less species of weeds as compared to their normal crop counterparts, respectively, along with the reduction of the population of insects such as bees and butterflies.

By contrast, the recent issue on GM crops in the US is the increasing use of regular herbicides in the fields planted with GM crops. According to the 2003 report by Northwest Science and Environmental Policy Center (Government \& Policy Concentrates, Chem. \& Engineering News, p. 27, December 8 issue, 2003) (www.biotechinfor.net/technicalpaper6.html), a reduction of the use of regular herbicides was achieved in 1996-98 among fields planted with GM corn, soybean and cotton. However, by 2001-03 period, the use of herbicides increased by $\$ 75$ million, mostly to combat the increasing infestation and resistance development of weeds in those fields. The main point of emphasis of this report is the question on the economic benefit of planting GM crops, not on the diversity of weed ecosystem in those fields with GM crops. These cases serve as good examples of the importance of the social attitude in accepting new practices in pest control. Issues raised in this type of cases should be anticipated and addressed proactively to avoid unnecessary strains and adverse publicities.

\section{INTRODUCTION OF PREVIOUSLY UNTESTED APPROACHES TO REGISTER ESTABLISHED PESTICIDES}

It must be pointed out that even with established pesticides new issues could be raised when hitherto untested approaches are introduced for the purpose of registration or safety assessments. A good example may be the recent request of the use of human experiment data for the purpose of registration of organophosphate insecticides. ${ }^{5)}$ In this case, human volunteers have been tested for their response to low dose exposure of organophosphates in order to establish a no adverse effect level in humans. A presumed advantage in using human subjects in such cases would be the removal of the 10 -fold uncertainty factor mandated for the use of animal data in assessing human toxicity of given pesticides. It is interesting to note that in this case it is the American scientists who opposed the above petition, rather than the European counterpart. The request has been denied by the Committee sponsored by the National Academy of Sciences in the US, and as a result, the company which sponsored the study has decided to stage a lawsuit based on the acceptance of human data by the European Union. The stated reason for the rejection by the above committee has been cited to be the inadequacy of the test protocol to arrive at the no adverse effect calculation, rather than the use of the human subject. Nevertheless, this case raises the point that new, hitherto untested approaches in pesticide registration is likely to raise a new set of questions as well.

\section{CHANGING SOCIAL ATTITUDES AFFECTING PESTICIDE SAFETY ISSUES}

While the above examples indicate that societies could resist changes demanded by scientists who develop new technologies, there are also examples that societies themselves also force changes in the way pesticides are regulated mostly based on the shift in the social psychology. Some of those could occur gradually over the course of years, and other could take place suddenly as the result of accidental exposures to pesticides, or discovery of their unexpected adverse effects.

A good example could be found in the recent changes in the attitude of people towards children's health in the US. Such changes are the result of many news releases by the media relative to the increasing incidence of modern diseases involving children. According to the special issue of Newsweek magazine on children's health, for instance, the incidence of allergy and asthma attacks among school children increased by $33 \%$ (since 1996) and by $60 \%$ (since 1992), respectively. The number of school children taking sick days also increased by $150 \%$ (since 1980). The most startling statistics is the reported cases of autism which roughly doubled in number since 1998. To be sure no evidence exists to indicate that any of these increases are due to normal uses of pesticides. Nevertheless, it is clear that the enactment of a new legislation, called the Food Quality Protection Act (FQPA) of $\left.1996^{6}\right)$ is based on the concern over children's health, since it mandates that, unless proven otherwise, 10x uncertainty factor will be taxed on all registered chemicals which could be found in food and drinking water to account for the possible difference between children and adults in their susceptibilities towards poisons. It is true that toxicologists have not been paying as much attention to the vulnerability of children as that of adults in the past. Therefore, the public has the right to demand that more efforts be made to study this subject area.

Recently an issue on the safety of the use of arsenic treated woods in playgrounds in the US has been raised. Most of the woods used in the outdoors in the US have been treated with the combination of copper, chromium (III) and arsenic (V) (abbreviated as CCA-treated woods) to prevent them from decaying. Most of children's playground equipments have been 
built using these CCA-treated woods. Not only that in some locations polished wood chips have been used to cover playgrounds (called "mulch") which could become the object of children's chewing. ${ }^{7)}$ All together 360,000 metric tons of arsenics are imported into the US for the purpose of wood treatment, and therefore the total arsenics present in those woods are estimated to be substantial. The main argument against total banning of CCA-treatment is that in those treated woods arsenate actually forms a stable 2 to 1 complex with chromium (V) which is not likely to be readily available. Indeed, X-ray study results support the existence of the complex and dermal absorption study on the dry powder obtained through surface scrubbing in monkeys supports the view that the extent of direct skin absorption of arsenic is small. Nevertheless, direct feeding of those powder preparations to test animals produces arsenic residues in urine. Furthermore, small amounts of arsenite (As III) have been detected in soil samples around treated woods, indicating that arsenic, even though it forms a stable complex at the beginning, eventually could change its form to leach out of those weathered woods. ${ }^{8)}$ At this stage of writing, the US EPA is considering banning most of the uses of CCA.

\section{SCIENTIFIC INFORMATION CREATING NEW ISSUES}

It is understandable that often new scientific discoveries are picked up by the mass media, and some of those are used to create new issues. Certainly the principle that science is the driving force of decision making processes of the society itself is sound and worthy of the attention of the media. The important point in understanding this particular type of new issue is that seldom the original reporting itself is the final settlement of the issue itself. Historically, science has shown again and again the collective ability of scientists to first digest new information, second to critically re-examine the evidence, third to consider alternative explanation, fourth to conduct additional experiments, and finally to place the findings into proper perspectives within the history of the development of that particular scientific field involved. Perhaps, some actual examples might help understanding these processes better. The discovery of many organochlorine insecticides to cause hyperplasia of hepatocytes in mice in the 70s has been picked by the media, and widely reported, resulting in the total banning of those based on suspected liver cancer potentials in many countries. Today the experts do not view this type of hepatocellular carcinoma in mice occurring at the maximally tolerated doses of xenobiotics as a truly carcinogenic indication. ${ }^{9)}$ Indeed epidemiological evidence indicates that there is no concrete relationship between exposure to those organochlorines and the incidence of liver cancer. It must be noted that it took many years to resolve this issue, and therefore it is not possible to assume that every new issue will result in a satisfactory resolution in a short time.

Probably one of the most watched recent discoveries in pes- ticide science could be the case of identification of neuropathy target esterase (NTE). ${ }^{10,11)}$ It has been picked up by the media and widely reported as the new problem found against organophosphate insecticides. These workers tested the toxicity of ethyl octylphosphonofluoridate (EOPF), a known agent to cause delayed neurotoxicity (OPIDN), against nte $+/-$ mice and found that it caused hyperactivity in those as compared to control. Certainly it is an important breakthrough in this field where scientists have been struggling for a long time in search of this elusive target of delayed neurotoxicity. It is extremely gratifying to finally know the identity of the proposed target enzyme, a lysophospholipase which shows many of the properties of the NTE. The authors should be congratulated for their tremendous achievement. Having stated clearly the scientific value of the above discovery, it is also important to point out that it immediately raised new questions as well. According to O'Callaghan (2003) the hyperactivity symptom observed by inhibiting lysophospholipase in mice after 3 days is not the OPIDN. In fact mice have never been found to exhibit OPIDN symptoms. Furthermore, the above observation does not fit to the previously held view that it requires the process of "aging" of phosphorylated enzyme to show the phenomenon of OPIDN. ${ }^{12)}$ It is not totally impossible to reconcile these differences in opinion by hypothesizing that in hens, the test animals which show OPIDN inhibition of this same enzyme results in aging and delayed neurophathy, but the questions must be solved by additional experiments. Till then, the issue raised by the media and the affected governmental agencies cannot be resolved scientifically.

Another good example is the case of rotenone induced Parkinson's disease. It has been initially shown that rotenone causes Parkinson's disease in rats when administered in a chronic mode. ${ }^{13)}$ Later it was established that not only rotenone but also paraquat can cause the similar symptom when administered systematically. ${ }^{14)}$ The cause for such an action of rotenone has been identified to be the oxidative damage due to its specific action of the brain mitochondrial complex 1 , opening up the possibility that many of the pesticides which act through the mechanism of inhibiting complex 1 could also cause Parkinson's disease. ${ }^{15)}$ Indeed, in a poster presented in a recent Society of Neuro Science Meeting, by the same research group from Emory University, 3 diazirinyl acaricides fenpyroximate, pyridaben and fenazaquin have been reported to affect complex 1 in an in vitro test to detect potential toxicants for Parkinson's disease. ${ }^{16)}$ It must be clearly mentioned that in this case the authors themselves are careful to point out that such in vitro data are meant only to prove the principle of the target interaction by these pesticide, and not to implicate them for Parkinson's disease. The pressing need is, however, to show clearly whether these pesticides can pass through the mammalian blood brain barrier to reach their putative target in the brain or not.

While the above examples happened to highlight the cases 
of new findings raising more questions, there are the other types of cases where new scientific evidence can settle the old issues. One prominent example is the old issue of whether various pesticides, reported in vivo to act like estrogen, could synergize estrogen at the estrogen receptor level, ${ }^{17)}$ or not. The above finding was immediately questioned, ${ }^{18,19)}$ but efforts by many scientists have unambiguously established that those pesticides do not synergize estrogen, finally settling the old issue. ${ }^{20)}$

\section{COUNTER FORCES BARANCING THE INCREAS- INGLY COMPLEX REGULATORY REQUIREMENTS}

Not too surprisingly there are counter forces to prevent all those issues from getting out of hand to cause totally chaotic situations. One clear-cut example is that of the new attempt to reduce the number of animals used to determine $\mathrm{LD}_{50}$ values in all drug and pesticide testing for registration. The new method being proposed is called "Up-and-Down Procedure" for toxicity testing. ${ }^{21)}$ This new initiative is likely the result of the animal right movement which has been challenging the need for excessive in vivo testing in toxicology. This method suggests the use of only 2 to 3 animals per test group initially at the dose increment of $3.3 \mathrm{x}$ intervals. When some mortality is recorded in a given dose, two closest doses, one at a higher (Up) and the other at a lower (Down) dose should be tested with a higher number (e.g. 10 to 25 ) of animals. This recommendation is based on the accepted principle of log probit mortality analysis that the value closest to $\mathrm{LD}_{50}$ shows the highest statistical reliability. Experts in statistical science agree that this abbreviated form of $\mathrm{LD}_{50}$ estimation is no less reliable than the regular test method. At this stage the only objection for adoption of this approach in toxicology comes from the wildlife toxicologists who must deal with genetically uneven populations in the field.

Another type of major counter forces comes from globalization of pesticide regulations as related to the push for creating free trading economic zones in the world. Complex and redundant requirements hinder free trades as well as increase the cost of crop and food protection. Harmonization of rules involving many socially different countries tend to gravitate to the direction of settling at the minimum common denominators, although the commonly accepted rules also tend to follow those of major economic powers.

Finally, it must be stressed that science and logic can be the major force in settling issues and thereby contributing to the satisfactory resolution of complex and even extremely controversial issues. In the case of children's health as related to the question of relative susceptibility of children and embryo to organophosphates, it was the scientific committee specially appointed by the US National Academy of Sciences that issued the initial overall assessment that there is no universal trend to indicate that children and embryos are more uniformly susceptible to organophosphate pesticides than adults. $^{22)}$ The Scientific Advisory Panel of the USEPA has also reached a similar conclusion, except that the scientists on the panel noticed the phenomenon that the number of the muscarinic receptor in children declines more significantly than that in adults in a side-by-side animal test, indicating that there could be cases where future studies with more thorough investigative approaches uncover hitherto unknown vulnerabilities of children and embryo.

\section{CONCLUSIONS}

There is no way for anyone to avoid facing ever increasing new safety issues in pesticide science. The use of pesticides will keep increasing world wide, new chemicals and technologies are invented every year, an increasing number of new scientific discoveries are made and furthermore the attitude of the society keeps changing in dynamic fashion. Thus, it is important to first understand the reasons why those new issues are raised. Second, the pesticide scientists must recognize the pattern of their appearance. Once this is done, they must study the case history of social processes taken to arrive at reaching the eventual resolution in each case. Only then one can make the right decision at the appropriate timing. The most important lesson may be that social psychology of a given time period can play the major role in deciding the overall regulation of pesticides in any society. The big difference in the response of the public towards newly introduced GM crops between Europe and the US illustrates this point. The second conclusion is that scientists can play a very important role is resolving these complex issues. It must be emphasized that reliable scientific evidence form thoroughly done research work, followed by very logical explanations are always accepted in resolving the differences in opinions and they do indeed contribute in relieving the public from the fear of the unknown. Identification of key element in resolving each complex issue must be the most critical step for the responsible scientists.

\section{ACKNOWLEDGMENTS}

This article has been prepared during my sabbatical stay in the laboratory of Professor Hisashi Miyagawa at Kyoto University. I would like to thank him as well as his laboratory staff for their hospitality, making my sabbatical a most enjoyable experience. Supported by grant P01-ES05707, for the Community Outreach and Education Program from National Institute of Environmental Health Sciences, Research Triangle Park, North Carolina.

\section{REFERENCES}

1) A. Cockburn: J. Biotechnol. 98, 79-106 (2002).

2) S. L. Taylor and S. L. Hefle: Curr. Opin. Allergy Clin. Immunol. 2, 249-252 (2002).

3) J. Pickrell: Science 301, 447-448 (2003).

4) M. G. Schults, T. Diehl, G. P. Brasseur and W. Zittel: Science 302, 524-543 (2003).

5) T. Reichhardt: Nature 421, 200-201 (2003). 
6) P. J. Landrigan, C. A. Kimmel, A. Correa and B. Eskenazi: Environ. Health Perspect. 112, 257-265 (2004).

7) T. G. Townsend, H. Solo-Gabriele, T. Tolaymat and K. Stook: Sci. Total Environ. 309, 173-185 (2003).

8) D. A. Belluck, S. L. Benjamin, P. Baveye, J. Sampson and B. Johnson: Int. J. Toxicol. 22, 109-128 (2003).

9) S. Chevalier and R. A. Roberts: Oncol. Rep. 5, 1319-1327 (1998).

10) G. B. Quistad, C. Barlow, C. J. Winrow, S. E. Sparks and J. E. Casida: Proc. Natl. Acad. Sci. USA 100, 7983-7987 (2003).

11) C. J. Winrow, M. L. Hemming, D. M. Allen, G. B. Quistad, J. E. Casida and C. Barlow: Nat. Genet. 33, 477-485 (2003).

12) M. K. Johnson and P. Glynn: Toxicol. Lett. 82/83, 495-463 (1995).

13) R. Betarbet, T. B. Sherer, G. MacKenzie, M. Garcia-Osuna, A. V. Panov and J. T. Greenamyre: Nat. Neuro Sci. 3, 1301-1306 (2000).

14) R. Betarbet, T. B. Sherer and J. T. Greenamyre: Bioessays 24,
308-319 (2002).

15) T. B. Sherer, J. H. Kim, R. Betarbet and J. T. Greenamyre: Exp. Neurol. 179, 6-8 (2003).

16) T. B. Sherer, J. R. Richardson, A. V. Panov, G. W. Miller and J. Greenamyre: Abstract Program No. 95.18, Society for Neuroscience, Washington DC (2003).

17) S. F. Arnold, D. M. Klotz, B. M. Collins, B. M. Vonier, L. J. Gillette, Jr. and J. A. McLachlan: Science 272, 1489-1492 (1997).

18) J. Ashby, P. A. Lefevre, J. Odum, C. A. Harris and E. J. Sumpter: Nature 385, 494 (1997).

19) J. Kaiser: Science 284, 1905 (1999).

20) K. Graumann, A. Breithofer and A. Jungbauer: Sci. Total Environ. 225, 69-79 (1999).

21) A. H. Lichtman: J. Pharmacol. Toxicol. Methods 40, 81-85 (1998).

22) L. R. Goldman: Environ. Health Perspect. 106 Suppl. 3, 857-862 (1998). 